\section{Richmond issues challenge}

\section{London}

"A national disgrace" is how Sir Mark Richmond, chairman of the Science and Engineering Research Council (SERC), described the low pay of junior scientists in Britain, in an address to launch Nature's Manifesto for British Science last week (Friday, 13 September). Speaking in a personal capacity, Richmond challenged Kenneth Clarke, the Secretary of State for Education and Science, to increase scientific salaries sharply and immediately or face charges of "anti-intellectualism".

"Certainly the government seems to see no electoral disadvantage in denying our research workers the rewards their intellectual gifts are due," he said. "The Secretary of State ... gives every indication of priding himself on his qualities as a minister. ... Let him get the resources to provide the opportunity and the remuneration needed to make a decision by a person to go into a career in science no longer an act of total self-immolation."

But salaries are just one aspect of British science eroded by successive governments. More insidious is the steady attrition of funds experienced by the Universities Funding Council (UFC) and the research councils, the two parts of the 'dual support system' that underwrites most of British academic science.

In this system, the government (through the UFC) provides research facilities, while the research councils inject funds for particular projects. The system has been a success, but during the 1980 s researchers have found it hard to make ends meet. Richmond blames the "failure" of the government to account for inflation in its less able to meet. their various obligations. allocations to the UFC.

The plight of university research has been masked to some extent because research councils have taken up some of the slack. Although the number of teaching staff in universities remained more or less constant throughout the $1980 \mathrm{~s}$, the value of alpha-rated proposals for research council grants more than doubled, from $£ 30$ million in 1980 to a peak of more than $£ 70$ million in 1987, a demand that the research councils have been progressively

The research councils are also being asked to meet the costs of overheads something that universities, through the UFC, should be doing. Having done for the universities, the government has focused its attack on the research councils themselves - a double blow to the dual support system. 'Stop-go' funding has led to much unnecessary disruption as the research councils have struggled to meet

Some have argued that the dual support system should be abandoned in favour of research-council-funded institutes 'at one remove' from universities. This would be "disastrous", says Richmond, because it would deny undergraduates the opportunity to move smoothly into research: "It is impaired opportunity which is one of the most baleful influences on scientific research in our universities at present."

Richmond argues for an improved dual support system in which the costs of research and teaching are properly accounted for as well as for the splitting of the recently merged UFC and PCFC (Polytechnics and Colleges Funding Council) into

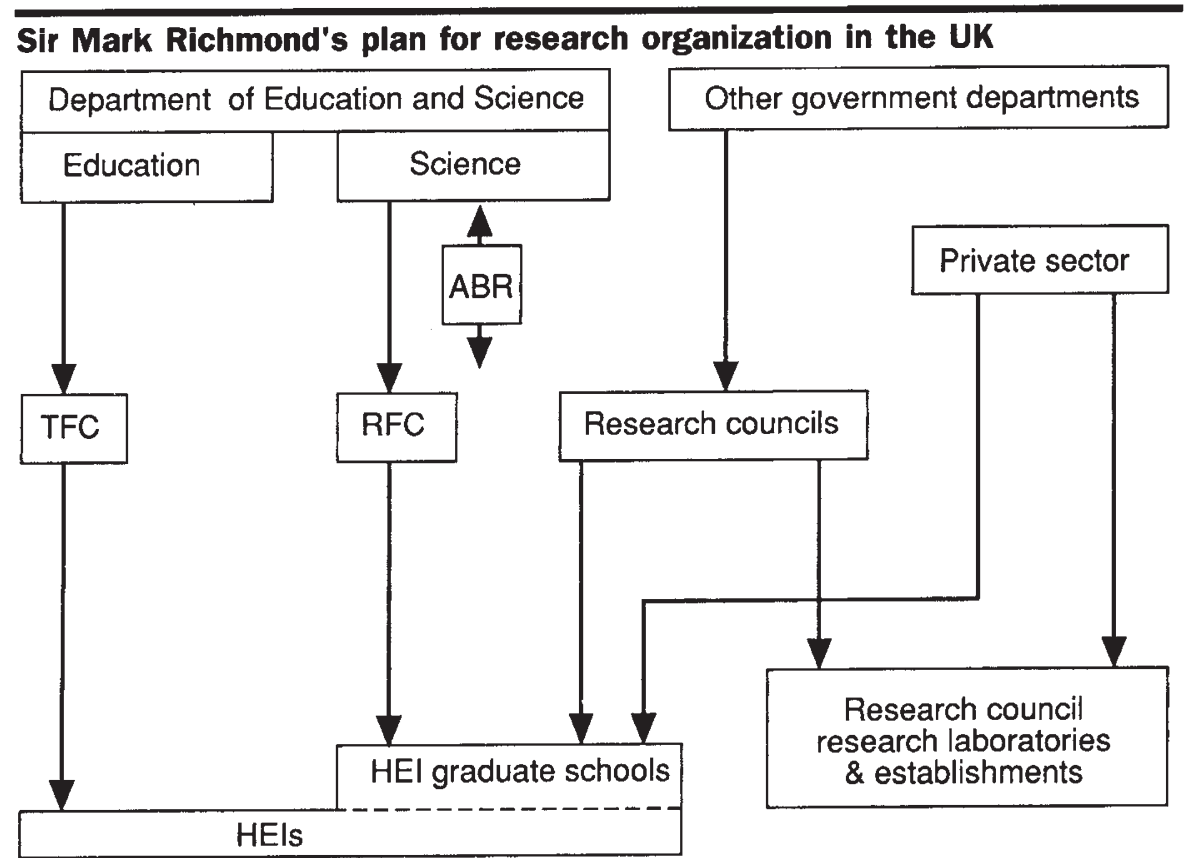

ABR=Advisory Board for Research; $\mathrm{HEI}=$ Higher Education Institution;

$\mathrm{RFC}=$ Research Funding Council; TFC=Teaching Funding Council
Teaching (TFC) and Research (RFC) bodies (see figure). University research money and research council funds would be channelled through graduate schools that each university might be obliged to create as a separate 'cost centre' before it could receive funds for research.

In the meantime, the Advisory Board for the Research Councils (ABRC) would be replaced by an Advisory Board for Research (ABR) that would advise the Secretary of State on matters of policy, but otherwise let the research councils get on with the job.

But without the realization in government that the research base is a cultural asset, such schemes are rather like rearranging the deck-chairs on the Titanic. An extra $£ 100$ million annually to oil the wheels would lift flagging morale, quite apart from a boost in the total cost of

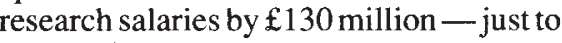
begin with.

But Richmond takes issue with Nature's Manifesto in his support for the diversity of views fostered by several different research councils. Nature's proposal to scrap all except SERC and incorporate the others as agencies of government departments came under fire from another quarter; speaking from the floor, Sir Gordon Cox, the 85-year-old ex-secretary of the then Agricultural Research Council noted that the research council idea was proposed (by the Haldane Report of 1918) specifically as a defence against meddlesome civil servants.

These views were echoed by Jeremy Bray, the Labour Party's spokesman on science, who was the only representative from a political party present. He criticized the Manifesto's recommendation for a new government to spend in its first year "only what the present planning figures allow for" as "hardly a clarion call".

Science, he said, will never be high on the political agenda so long as cash calls are seen as "jobs for the boys". The science lobby should emphasize the value of its output, rather than its need for input. In the runup to a general election, scientists should ask their prospective political representatives a few difficult questions.

Personal stories from the 'shop floor' illustrating the economic depths to which young researchers must sink in pursuit of their goals were particularly telling.

One speaker said there is no guarantee that young researchers, fresh from their PhDs, will be able to secure even the pitifully low salaries on offer for any length of time. Perhaps more than money, researchers crave some kind of career structure. At present, the career of a scientist is as secure as that of an actor, except that the pay is even worse. Scientists, as Richmond noted, do science for the love of it, but should they "be abused by taking advantage of their obsession to pursue good science"?

Henry Gee 